and free use of the lancet; but Bouillaud, in France, with his bleeding coup sur coup in pneumonia, introduced a still worse method, so that Dr. 'Tully wrote, "the lancet is a weapon which annually slays more than the sword."

Those who were students in the Paris hospitals in the early fifties will remember the pewter porringer on a shelf at the bead of every bed to receive the blood of a patient; and if you will examine that admirable work, "Le Guide du Medeciu Practitien," of Valleix, Baillic̀re, Paris, 1853, you will find under the head of treatment, "La Saignée" given the first place in nearly every disease in the five volumes. These were bad fashions.

But for more than forty years the practice of venesection has entirely goue out of use in our largest hospitals and among our most distinguished physicians. So much is this the case that the sugrestion to "bleed" is met by doctors and patients with incredulous surprise, as though it were question of a capital operation ii) surgery. Every radical departure in treatment has been supported by some theory. The "change of type" theory, which grew, I believe, out of the Brunonian system, was brought forward to upbold the neglect of venesection. This theory was another of those vague speculations, chiefly dialectic, whose cloudy futilities have from time immemorial obscured the pathway of medical science. It went into the dustheap long ago, but the practice of bleeding, theory or no theory, has been discredited.

In that most excellent work, "The Principles and Practice of Medicine," by William Osler, New York, 1894, we read, "Pueumonia is one of the diseases in which a timely venesection may save life." $\Lambda$ ud speaking of "Emphysema," he says, "On more than one occasion I have saved the lives of persons in this condition by venesection." And under "Clironic Valvular Disease," "This is the occusion in which a timely venesection may save the patient's life." Also, at page 1019, Osler states that the life of Dr. Weir Mitchell, when a young man was saved by free bleeding in sutn-stroke. I can recall in no modern work on "Theory and Practice" or "Therapeutics," a similar statement in regard to the effect of any drug.

I would say to you in the emphutic language of Rufus Choate, "Gentlemen, there is not one jot, not one tittle, not a scintilla of evidence which can impeach the testimony of this witness." In the cases cited by Osler the course of nature tends inevitably and swiftly to death. The effect of the remedy appears as indisputable as that of chemical reaction. For what purpose are we physicians if not to save human life, if it be in our power to do 80 ! $\Lambda$ re we to stand by and see our patients dying - as it were drowning, and we refuse to throw the rope which we hold in our hands - in obedience to the dictation of a heartless, senseless fushion!

('To be continued.)

'Yhy New Woman and the Wheel. - A writer in a St. Louis contemporary says that the bicycle " is equally if not more beneficial to young girls with scanty, delayed or irregular menstruation, who are developing into manhood, than any other deviation from the normal that the female sex is aflicted with." The opponents of the wheel contend that this is just the trouble, that girl riders develop into manhood.- Medical Record.

\section{Briginal \$rticleg.}

\section{S'TANIDARDS OF FORM ANI) COLOR-VISION IN RAILWAY SERVICE. 1}

HY CIARLES IT. WHLIAMM, M.D., BOSTON.

By normal vision is meant such acuteness of perception of form by the eye that it can recognize letters or symbols which subtend a visual angle of five minutes, and whose breadth is throughout equal to onefifth of their height. This standard was established years ago by Prof. H. Suellen, of Holland, who found by a large number of experiments that the average healthy eye could easily read such letters. Many eyes, especially those of young people, have a greater acuteness of sight than this, but, on the whole, it fairly represents the average vision of a healthy emmetropic eye, and has been accepted both in Europe and in this country as the standard in general use.

'The letters of Suellen's test-types, to be read at a distance of twenty feet, should be three-eighths of an inch $^{2}$ in height, and if the person under examination reads them with each eye separately at that distance withont glasses, the other eye being covered by a card held tirnly against the nose, we call his vision normal, or 20, in each eye. If he is obliged to approach to ten feet from the letters in order to read them we call the vision one-lialf of normal, or $1 \%$. In practice letters of different sizes are printed on the test-carids and over each line is printed the distance at which it can be seen and read at the standard angle of five minutes, that is by a person having normal acuteness of vision. If we find that at twenty feet the smallest letters which can be easily read are on the forty-foot line the vision will be 20 , or one-half. The acuteness of sight is measured by Snellen's formula $V={ }^{\prime}$, , in which $V$ stands for the vision; $d$, tho distance at which the test-types are recognized; $D$, the distance at which they cas be seen by the normal eye under the standard angle of five minutes.

In ordinary disease, or in errors of refraction, we use these test-types to mensure the progress of the case, or the best results from glasses; but in certain forms of employment, as in the railway service, in which keen vision is required, they are used to decide whether a person is qualitied for the work he will have to do, and in these cases the question at once arises as to what acuteness of vision should be required for such work. A single standard will not answer. A greater acuteness of sight will be necessary on the head end of a truin than would suffice for switchmen. Aguin, when a man applies for work in connection with the operation of ralway trains he should be required to have a greater acuteness of vision than the amount which will suffice to allow him to continue the work with which he has become thoroughly familiar after years of service. Thus we should have two standards, the higher for entrance to the service, and the lower, which would be within the safety line, and would be suflicient to allow a continuation of employment.

'The principal hardships to employees in vision-tests has come, not from enforcing a high standard for en-

1 Rend before the Boston Socioty for Modienl Improvement, Fobruary 8,1897 .

2 'The measuromonts in this pnpor aro givon in fmolies instead of in his metrieal form, as the formor are in gonerial use anong the railronds. 
trance into the service, but from discharging men after years of faithful work, for some defect which the railroad company might have discovered at the time they were employed, if a proper examination had beeu made at that time. 'Therefore, it is important, both to the company and to the men, that the methods used and the standards adopted should be such as to exclude men who are not fitted for the work, and to prevent their wasting time in learning a business they may have to abaudon; also, in cases of defective sight or color-sense acquired in the service, to enable the company to relieve such employees, or transfer them to other duties, before they have become a danger to themselves, their fellow-employees or the travelling public.

If we look through the standards required to-day on various ruilways and in varions countries, we shall at once see in what an unsatisfactory condition this matter now stands. In some countries the goverument regulates the matter, in others the companies adopt their own rules; and it is noticeable that some of the highest standards are those voluntarily adopted by the roads themselves.

In Holland, these matters have been more carefully worked out than elsewhere, and oculists of the highest standing in their profession have been called on to formulate rules for these examinations and to fix the standards. They require for Class $\mathbf{A}$, enginemen or firemen, with both eyes open, normal vision; with each eye separately, the other being covered, normal vision in one eye and not less than one-half in the other, without glasses; also normal refraction. For Class 13, station-masters, conductors, brakemen, switchmen, etc., with both eyes open, normal vision without glasses, free from hypermetropia of more than one dioptre; with each eye separately, in one eye normal vision, in the other not less than one-fourth, without glasses. 'The vision is measured by Suellen's testtypes.

In England, a committee of the British Medical Association, after careful investigation, recommended in their report in 1892 , for Class $\mathbf{A}$, engine-drivers, cleancrs, firemen, signulmen and pointsmen, in one eye normal vision and refraction, in the other eye not less than one-half of normal vision, without glasses. For Class 13 , all othor situations in the executive service concerned with the moving and sigualling of trains, with both eyes open, visual acuteness of not less than two-thirds of normal, without glasses, provided that neither eye has less than one-third of normal vision without glasses, using Suellen's test-types.

In Belgium, for Class $A$, in one eye 20, in the other not less than $: 0 \%$; for Class B, in ove eye 20 , in the other not less than

Iu Bavaria, for Class A, 20 , without glasses, is allowed; this class here includes all outdoor employees.

On the New York Central and Hudson River Ruilroid, for a first-class certificate, vision of at least $9_{30}^{0}$ is required; but if one eye hus 20 and the other ${ }_{40}^{20}$, it will answer. For a second class certificate, for yard service only, not less than $\underset{40}{20}$ is required; but if one eye has 20 and the other $20 \%$ it is accepted for a second-class certificato. On the Pennsylvania System ${ }_{20}^{2}$ in one eye and not less than ${ }_{0}^{0} 0$ in the other is considered satisfactory, with or without glasses. On the Burlington System, for entrance in to the engine service, ${ }_{20}^{\prime \prime}$ in each eye is required; and for the train and yard service 20 in one eye, and not less than 2.8 in the other eye, without glasses in all cases; each eye being tested separately.

It will be seen from the above that the standards of vision vary in different places from ${ }_{20}^{0}$ or normal vision in each eye, down to $\% 0$ in each eye for the first class. In some cases provision is made for re-examination, but in many places no separate standard is required for this. 'The test in geveral use is Snellen's testtype, although in England some roads use the army test-card, with dots instead of letters.

.'The principal objection that I have found to the ordinary Snellen letters, for this work, is that they are all printed on one card, and it is not difficult for men who are to be tested to provide themselves with copies of the card in order to memorize the letters. In one case a man read easily the $x x$ foot line at twenty feet who could not read either the $x \times x$ or $X L$ line at twenty feet when called on to do so unexpectedly by the examiner. In order to overcome this difliculty, and also to provide a more convenient form of test-card, 1 had the letters of standard sizes printed on a series of separate cards, one line on each card, and for each distance had three cards with a different arrangement of the letters on each. In testing a person, one of the $\mathbf{x x}$ foot cards is placed in a good light twenty feet from him, and he is asked to read it; if he does so correctly, another of the $\mathrm{xx}$ foot cards is shown for a second trial. He caunot tell which of the cards he will be asked to read, so that even if he had memorized them all, he would have to see the letters in order to read the cards correctly, and as there are no letters of a larger size on the same card he could not recite from memory the smaller letters by means of the larger letters that he could see. If he cannot read the $\times x$ foot line at twenty feet, then the $x \times x$, the $x I$, the $\mathrm{L}$ or the L.XX foot cards are shown in succession until letters are found that he can read; or if he cannot read the LXx foot line at twenty feet he is brought nearer until a point is found where it can be read; or if he cannot see it at any distance, the fact is so noted. This test has been in use on the Burlington System since 1893, and has given good satisfaction.

I have recently been experimenting with another test-card with figures made to represent a line of semaphore signals, such as are often placed on a bridge crossing the tracks, as at the entrance to a union station. On this card the length and breadth of the arms correspond to the height and breadth of the Snellen letters for $\mathbf{x x}$ feet, und also correspond when looked at from a distance of twenty feet to the size of a staudard semaphore arm when seen at a distance of half a mile. I find when the relative visibility of this signal card is compared with the corresponding Snejlen letters, that the card of signals the same size as the $x \times$ foot letters can be seen clearly as far as the XXX foot letters. For, with signals, the only point is to recognime quickly and surely the position of the semaphore arm, as to whether it stands horizontally at danger, or at an angle with the horizontal at safety; whereas with the letters small differences of shape must be recognized, and the letters $C, G, D$ and $O$ are eusily confounded; such mistakes shouid not reject a candidate. We can therefore safely allow a less degree of vision as tested by letters, especiully on re-exumination, than 20 , and yet be within the safety limit for signals.

A ruilroad company should require normal vision, $\frac{28}{2}$, in each eye, without glasses, and less than two 
dioptres of hypermetropia of all persons seeking employment in its engine service who will be required to act at any time as enginemen or firemen. Plenty of such men can be had, and the company cannot afford to accept and educate men who are lacking in normal vision when they begin their work. After years of service the requirements may be reduced for Class $A$ to not less than 38 of normal vision in oue eye and 28 of normal in the other, each eye being tested separately without glasses; but less than this should not be allowed on the liead end of a train.

The same standards should be required of men in sigual towers and in charge of interlocking signals and switches and drawbridges; but for the general train and yard service lower standards may be allowed. For entrance to the train and yard service 20 , or normal vision in one eye, and not less than 20 in the other, without glasses, should be required. After years of service, on re-examination, this might be reduced to not less than 38 in one eye and 30 in the other, without glasses.

In addition to reading the test-letters by candidates for employment, a simple test for refraction should also be used in all cases. We may leave out of the question the conditions of myopia and astigmatism, for, if present in any amount, they would cause enough defect in sight to bring the vision below the required standard; but a young man of twenty-one years of age, or thereabouts, may be able to read easily the $\mathbf{x x}$ line at twenty feet with each eye, and yet have a hypermetropia of two dioptres, or more, which by the time he is forty-five years old, or sooner, will reduce his visual acuteness for distant objects below the standard required, and it is not just to sucl men to accept them for the service and then retire them when they are too old to learn another business, because they cannot come up to the visual standard required without glasses, although they may have had normal vision in each eye when they applied for work. Such hypermetropia can be easily detected by asking the applicant to read the $\mathrm{xx}$ line of test-letters on another card at twenty feet, while looking through a convex lens of two dioptres, or eighteen inches focus, each eye being tested separately. If with cach eye he can read the letters correctly through this glass, he should be rejected, for it shows he has a hypermetropia of two dioptres, or more, which, when his presbyopia becomes apparent, will be sure to impair his distant vision unless glasses can be used.

I recently had a case to examine where the vision of an engineer had been reduced to three-tenths of normal in each eye. 'There was no other trouble except a hypermetropia of three dioptres in each eye; and with proper glasses the vision was brought up to normal in one eye, and nine-tenths of normal in the other. He was trausferred to other work in which he could use his glasses; but in this case the simple test with a convex gluss would probably have shown the trouble at the first examination for entrance to the service, if one had been required at that time.

A periodical re-examination of the vision should be required of all men employed in the operation of trains or signals every three years, for the sight is often impaired by disease of the inner structures of the eye that may show no outward change; und such re-examinutions should be made before promotion, after serious illness or injury, after accidents which might have been due to defective sight, or when from exces- sive use of tobacco or other cause it is deemed necessary. The certificate of examination given to the man should state the date of examination, the occupation which the certificate covere, and whether or not any defect is found in acutevess of vision, color perception or hearing, and the certificate should be signed both by the examiner and the person examined. If the first examination is made by a competent person, according to approved methods, at the time of employment, no repetition of the tests for color-vision will be needed, unless it is found that the acuteness of formvision has become impaired; for in the cases of ac. quired dofect in color-8ense an accompanying defect in sight is found which will be brought out by a repetition of the test with letters on the test-caris. In such cases it may be well to repeut the color-tests, and to refer any doubtful cases to an approved expert. In cases of congenital defect in color-sense there is generally no impairment of the acuteness of form-vision.

In all examinations for sight, care should be taken to see that uniform and accurate test-letters are used, for within a month my attention has been called to sets of test-letters recently published in which there was a considerable variation in the size of the letters to be used at twenty feet on different cards issued by the same firm. Again, the illumination of the letters should be as clear and constant as possible; the card should be hung where it gets the daylight full upon it, but not in the sunshine or where the person reading it will have to look directly toward a strong light.

As to the relative frequency of defects in sight and in color-sense, we rejected on the l3urlington in six years 176 cases for defective color-perception and 344 for defective sight, most of these cases being applicants for positions in the service. In general it may be said that the number of cases of defective sight found on first examination for entrance to the service will be more than twice the number of cases of defective colorsense, but on re-examination defects in form-vision will be found while those for color will be extremely rare. The instructions of the Pennsylvania Railroad in regard to tests for vision, etc., also provide for an examination of the field of vision and the range of vision. It does not seem to me that these tests are necessary, especially considering the way in which they are usually made; and in the thonsands of reports that were sent to me on the Burlington, where somewhat similar tests are used, there was not a single case where a man was rejected for limited range or field of vision, in which the acuteness of sight was up to the required standard. The examination on the New York Central and Hudson River Railroad does not include either a test for the range or lield of vision. It is, however, well to have a reading-test in order to make sure that the person examined can read both print and written train orders at the ordinary distance. And I have known an engineer who was found by this test to be unable to read, although he had normal vision, knew his letters and could sign his name; he was in the habit of having his fireman read all train orders to him, but when his condition was discovered he was laid off until he could learn to read, and write more than his signature.

In regard to the use of glasees, the instructions of the Pennsylvania Railroad say, "If one eye has 200 or 1 , and the other eye not less than 20, or ${ }_{2}^{1} n$, with or without glusses, the sight may be considered satisfactory"; but no statement is made as to whether this 
will be satisfactory for an examination for entrance to the service, or only for re-examination, or whether glasses will be allowed on duty. It will be found in practice that glasses for distant vision cannot be worn on duty by enginemen and others whose duties require them to work out of doors in all kinds of weather; for stenm, rain, smoke and snow interfere seriously with their use. For this reason the acuteness of the distant vision for these men should always be tested without glasses. With cases of simple presbyopia it is different ; here the distant vision remains unimpaired, and when glusses are needed for occusional use, as in reading, they are not incompatible with good service. 'The presbyopia will have to be very considerable before it will interfere with the telling of time by the watch or the reading of steam or water gauges, without glasses.

'The standard examination for color-vision should include three things: (1) the naming of colored signal flags, and using them as test-objects for the Holmgren worsteds; (2) a test by comparison of colors by the Holmgren worsteds; (3) a test with colored lights as seen through openings of regulated size, which will form small images on the central part of the retina. The acuteness of color-vision varies considerably from a normal standard, as does form-vision. We may have a feeble color-percoption, an incomplete loss of colorsense, generally for red and green, or a complete loss of perception for these colors, and in rare cases a complete loss of all color-perception, in which the solar spectrum looks like a gray smear of varying shade but no color. The object of our tests is to discover the extent and churacter of the defects and whether they are sufficient in amount to disqualify, according to the standards adopted.

The test with flags shows whether the man can give the right name to the flags and can tell their use and meaning. It will also be desirable to use the flags as test-objects with the worsteds. It will often be found that correct names can be given to the flags even when consilerable defect of color-perception exists, for such men have learned to give a certain name to a certain perception; but when we come to use each flag, red, green, or white separately as a test-object and request that all colors be selected from the heap of worsteds which look like the flage, we may get among the reds a green or other color selected as looking like the red flag, or vice versa, in other words, with color's of certain intensities or shades, there may be an inability to distinguish between the red and green.

The test by comparison of colors, without naming them, selecting from a large number those which appear to the applicant like certain test-skeins, light green, and pink, according to the method proposed by Professor Holmgren, is the most satisfactory and easily applied of all the good qualitative tests; but it does not give a quantitutive test, and does not give a suflicient test for small central scotomata such as occur in tobacco cases. 'The test by Holmgren's worsteds alone will not in every case detect a serious defect in color-perception.

I have had recently a man who passed both the Holmgren and the 'Thomson tests without making a single mistake and who selected his colors without hesitation, but when examined by colored lights trans. mitted through small openings, or even with switchlight lenses before the lamp at twenty feet distance, he called a red light white in four different cases; he had a central defect in the retina, probably caused by the use of tobacco in excess, yet the area of the affected retina was so small that the retinal image of the worsted or the flags fell partly on the affected area and partly outside of it where the color could be at once recognized, but when the retinal image was reduced in size, as with the lights, it fell entirely within the affected portion und red lights were called white and sometimes green.

It will not do, however, to substitute the test with such lights for the Holmgren test, for the lights give little chance for comparison or for the selection of confusion colors ; and for ordinary cases of congenital color defect it would take a long and tedious examination to reach the same result that could be arrived at more quickly by the worsted test.

On the other hand, the test with lights, with regulated openings, should be used in addition to the worsteds, as is required in Holland. 'Iheir regulations for testing the color-perception of railway employees require a quantitative test in every case by Donders's method. In his instrument the light from a standard candle is allowed to fall on a disc carrying red, green, blue and ground glasses, and in front of this disc is a diaphragm with openiugs of $1,2,5,10$ and 20 millimetres in diameter; the colors can be changed by rotating the disc, and the man is requested to name the colors as seen through the smullest opening placed five metres from him. If he cannot do this, he approaches the instrument until the color can be distinguished, or a larger opening can be used. Professor Donders accepted the formula for the acuteness of color-perception as $=\frac{a}{A}$ in which $a$ is the visual angle at which the person examined sees the colors, and $A$ is the angle at which the examiner sees them. If the examiner can see the red and green lights through the one millimetre opening at a distance of five metres and the person examined only sees them at one metre his color-perception would be one-fifth.

In these cases we have to depend on the acuteness of color-sense in the eye of the examiner as the stundard with which the applicant is compared, and this standard may vary considerably in different persons. Again, the distance of the candle from the colored glass is an important factor, and the red can be scen by normal eyes with the caudle at a greater distance from the glass than with the green. In all signal lanterns, however, the light must remain at the sume distance from the lens, so that in testing railroad employees we may disregard this difference. Instead of taking so swall an opening as one millimetre for the standard test, it will be found better to use a two-millimetre hole, or about $B_{4}$ of an inch, and place the person to be examined at a distance of twenty feet from it. In this case the opening will subtend a visual angle of one minute at the eye, and will correspond to the width of the letters on the $\mathrm{xx}$ foot Snellen testcard used for that distance. If we make the other openings in our diuphragm $6^{7}+6^{3}, 1^{3}, 1, \frac{1}{3}$, and 3 of an inch in diameter respectively, we shall have a series of diameters that will nearly correspond to the width of the series of letters on the Snellen test-card, and which at corresponding distances would subtend the uniform angle of one minute.

If we consider as a sufficient standard for this test the ability to recognize red and green, either alone or combined with London smoke-glass to vary the in tensity of the light, and also white light, either alone or combined with the London smoke-glass, all seen 
under this standard angle of one minute, we can then use the other openings in the diaphragm to give a fraction which will represent the amount of color-perception as compared with this unit, just as in the case of form-vision. For instance, if the normal eye recognizes easily the colors through the two millimetre (or 6.1 inch opening) at twenty feet, and the eye examined only distinguishes them when the $i_{4}$ opening ${ }^{8}$ is used, we call his color-perception one-half of the standard. This is not exact and we cannot get with color-perception by our ordinary tests the same fine gradations of acuteness that we get with form-vision. We also find many eyes whose color-perception is more acute than this standard, just as we find eyes that can see the $x \times$ line of letters at a greater distance than twenty feet. But it furnishes us with an easy test having a direct relation to the standard of formvision, and one which is useful in detecting defects in the central portion of the retina.

About five years ago $I$ made an instrument on this principle which has given satisfactory results, and with it the standard switch-light lenses and semaphore glasses call also be used as confirmatory tests. In a paper by 1)r. Nuel, of Liege, published in 1895, he states that in Belgium in the confirmatory test they consider the color-sense as suflicient if the applicant distinguishes red and green through an opening of two millimetres at five metres distance when lighted by an ordinary kerosene lamp. In Holland, they require for color-sense in enginemen and firemen a power of distinguishing colors with both ej'es open, of not less than four-fifths, or, in each eye separately, not less than one-half; and for other specilied employments a color-perception of at least three-fifths with both oyes open, or not less than one-fourth in each eye alone. For re-examination, in the first class, the standard is dropped to at least three-fourths with both eyes open, or at least one-third with each separately; and in the second class, with both eyes, to at least two-thirds, or, with each eye separately, to at least one-fourth; and Donders's instrument is required to be used in all these tests. I used a Donders's instrument, made by Kuagenar in Utrecht for some time, but did not find it so convenient or satisfactory as my instrument with the larger openings and groater number and variety of glasses.

Even with the Holmgren worsteds it is possible to make a distinction between some of the greater variations in color-sense; for if a person is hesituting, picks up some confusion colors and compares them with the test-skein, perhaps selects them and afterward discards them, or picks up some of the true colors and after comparison rejects them, finally selecting none of the confusion colors, it shows that he has a feeble colorperception; if he selects with the greens some of the confusion colors, but with the pink or rose skein makes no mistake, it shows he has an incomplete defect; but if with the green skein he selects confusion colors in addition to the greens, and with the rose skeins selects with the rose colors some blues or violets, it shows he has a complete defect for red; or if with the rose skein he selects in addition to rose colors some greens or grays, it shows he has conplete defect for green.

On the Burlington System I found it best to have 8 The simes of oponings in this serios were ehosen becnuse twist

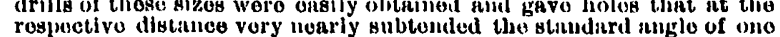
respuctivo
ininuto. each of the 117 colors of the Holmgren sets marked with a numbered brass tag, which could be used to make a record of the color selected by the applicant, just as in the 'Thomson's test, and each set being carefully prepared in my office the numbers and colors were uniform for the whole system, so that when the results of each examination were forwarded to me for approval they could be easily checked. It is necessary in this work to have the general supervision placed in the hands of some competent person who can see that the examiners are properly instructed, that they carry out their directions, and that the tests they use are uniform and are kept in good condition; otherwise there is danger that the examiners will become careless or that the condition of the cards and colors will deteriorate so that they caunot be relied on to give proper results.

So long as the red and green signals are used for night work (and no other colors are better adapted to this use), no applicant should be accepted for service in a position which will require him to use such sig. nals, who has incomplete or even feoble color-vision, and if these entrance examinations have been thoroughly carried out, according to Ilolmgren's directions, and also with transmitted lights, there will be no need of a repetition of these color-tests, except as before stated, where the form-vision has become impaired or where for some special reason it seems best to repeat the examination.

'The tests for both form aud color-vision should be made when the man is not fatigued by a long tour of duty or exposure; for it hus been found that the acuteness of both form and color-perception is diminished after two hours or more of engine work; after long runs and unusual exposure this temporary reduction in acuteness may be considerable and it furnishes an additional argument for insisting on a high standard for such service. If one-half of normal vision were to be accepted as a minimum in each eye when the person was rested and in good health, the conditions of service might easily reduce this to far below the danger point, but if a high standard is required tho vision may be temporarily reduced by fatigue without becoming dangerous.

In a report on the Sanitary Service of the Railways in Hollund, presented to the International Conference in Amsterdam in 1895, it is stated: "Experience has shown that since the examination for admission has been carefully made, the re-exuminations have shown scarcely any incapable men. It is also to be noted that the employees themselves in general recognize the utility and importance of these examinations." In a letter from one of the officers of the Burlington System, written to me Nuvember 18,1896 , he states that the operating oflicers of that system thoroughly approve of tho examinations for entrance to their service, which include not only the tests for sight, color and hearing, but also a general medical examination, which is made by the medical examiners of the road, who are all well qualitied medical men; and he also states that the general character and efficiency of the employees has been improved by these examinations, which are fairly and thoroughly made.

It seems to me that more can be accomplished in the way of improving the standards and methods used for testing sight, etc., by showing the operating officers of the railroals that it is for their own interest and for the interest of their employees to have such tests 
carefully made, and to use such methods as shull be just aud efficient, rather than by trying to force measures on the railroads through legislation, which is apt to be crude, and is met with opposition on the part of the road, and on the part of the employees, as being directed against their personal interests ; whereas proper methods rightly applied should meet with the approval of both officers and men.

\section{THE PROGNOSIS AND DURATION OF A'T- 'TACKS OF MEN'TAL DISEASE.' \\ BX HENRY IR. STWDMAN, M.D., BOBTON.}

There is no department of mental medicine that more closely concerns the general physician than the prognosis of insanity, as it is upon this point that his advice in such cases is of tenest asked. At the same time there is no other branch of the science with which he is less familiar. In fact, this paper is an endeavor to reply to requests from a number of practitioners for enlightenment in this direction.

Much of what follows is therefore an old story to the alienist, and perhaps to the neurologist. 'The much-mooted question, however, as to what constitutes acute and what chronic insanity, a matter of practical interest in the treatment, classification and disposition of the insane individually and en masse, as well as certain facts relating to the duration of acute attacks, both of which should be subjects of interest to those physicians whose work is more exclusively among the nervous and insane, will also be considered, as they seem not to have received the attention which their importance demands. But little reference will be made to the life-histories of the insane as regards permanent curability, as this is chiefly a clinical consideration of the immediate outcome of single and especially initial attacks and only in small part a statistical inquiry.

Statistics, although useful in elucidating other points relating to insanity, are of little help in prognosis. About all that can be gathered from them that is of real value on this point is the duration of hospital cases, and the fact that, as a general rule, those which are of short duration and are adraitted early in the disease, ure the most likely to recover. 'There are, to be sure, tables which give the number of recoveries from different forms of insanity; but as their classification is different in each hospital, only the results in the principal varieties form a sufficient aggregate for making an estimate. Hospital statistics, moreovor, cover but a part of the ground, and a vastly different idea of the prospect of cure would prevail if the undoubtedly large number of cases (chiefly of inclancholia), which recover without going to an asylum or even (as Blandford thinks) to a doctor, could be included.

Another complication which vitiates statistics of reported recoveries is recognized by asylum physicians generally, and that is tho personal equation of the observer. One superintendent will fully believe a patient to be cured whom another would regard as simply greatly improved; and it occusionally happens that two hospitals in which the same class of patients are received, both of which are managed in practically the same manner, and in which tho trestment and

1 Rond beforo tho Boston Socicty for Mtenlieal Improvomont, Apri 0, 1896, and tho Amorican Nemrological A Asociation, June 4, 1696. care of the inmates is materially the sume, will show a decided difference in the proportionate amount of reportel recoveries, which can only be accounted for in this way.

Agrain, patients often recover and remain well while in the hospital who break down very soon after their discharge on attempting to take up their old life, thus showing that their recovery was only relative to their surroundings - a hospital recovery. Such patients have not recovered in the true sense of the word, and as it is understood as regards other forms of disease.

The great scientific value of the statistical researches of 'Thurnan, Ilack 'Tuke and Eurle in the curability of insanty cannot be gainsaid, but the small percentage of permanent recoveries in institutions for the insane thereby established, certuinly has not stimulated us to work for the cure of separate attacks with the samo zeal and interest that have led to decided advances in the treatment of physical disorders, and which alone can make permanent cures more frequent. On the contrary, a somewhat pessimistic attitude toward insanity has resulted, and endeavors for the best provisions for the mass have overshadowed the investigation of separate cases - the study of the needs of the individual and the possibilities in the way of his cure.

Sir Dyce Duckworth, in a recent address ${ }^{2}$ upon "The Prognosis of Disense," remarks that at the present time, and for many years past, in spite of the extraordinary advances made in all branches of the sciences on which medicine depende - in epite, too, of the high degree of cultivation to which the art of medicine has attained in the last years of this century - the attention of physicians has been somewhat inadequately directed to the subject of prognosis in disease. He might well have added that in no department is prognosis more imperfectly understood than in that of mental disease. The principles - the elements of prognosis are wanting, and therefore the alienist is practically at sea in many cases of functional mental disorder, and has to fall back upon empirical predictions by symptoms or sets of symptoms, which aro often set at naught by some unexpected change in the course of the disease. 'To be sure, this happens often enough in physical disorders; and to be guarded in one's prognosis is the A B C of instruction in the practice of medicine. But nowhere is this caution necessary to such an extent as in functional disorders of the mind; and it is sufe to say that the longer the alienist lives the more he despuirs of making the right proguosis in individual cases, and the more he is inclined to "hedge" and to generalize.8 'The chief source of the difliculty is our ignorance of the pathology of insanity, no theory of which has a known demonstrable material busis in actual cerebral lesion, nor in specific physical manifestations, the steps of whose development are indicated by pathognononic symptoms following a definito course. The urray of classifications of insanity to which each new observer adds still another combinution, bears witness to this uncertainty.

" I'residentinl Achlress beforo tho British Medical Association, Brit.lsh Medien]. Jourmal, A uguHt, 18!5.

since tho ahovo was writien, tho writer ehanced to read clous tin's ndvice (Nental I)iseases, p. 116): "Bse ghardod in giving a prog-

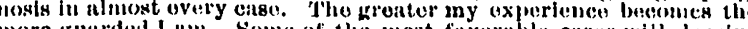
moro gunded I mm. Somo of the most finvorable cases will desentvo you, whilo some that look the most hopoless will recover, th til tho ease of 13. S. A., $\Omega$ phliont of mine who had betu soven years melan-

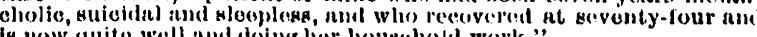
is now guite well and toing hier houscholil work." 